\title{
Recent Advances in Biomimetic Synthesis Involving Cyclodextrins
}

\author{
Y. V. D. Nageswar, S. Narayana Murthy, B. Madhav and J. Shankar \\ Organic Chemistry Division-I, Indian Institute of Chemical Technology, Hyderabad-500607, \\ India
}

\section{Introduction}

Modern bioorganic chemistry is interested in the mimicking of enzymes in their capability to bind substrates selectively and catalyze chemical reactions since biochemical selectivity will be superior to chemical selectivity in various aspects. Laboratory organic chemistry differs from that used in living systems to perform biochemical reactions. In general, organic chemists allow small reactive reagents to attack a free substrate randomly in a solution. The selectivity that is achieved is a result of selective reactivity of a particular region of the substrate or steric crowding or blocking certain approach directions. In contrast, biochemical reactions involving enzymes bind and then orient the reactants. Biochemical selectivity usually reflects such orientation, rather than the intrinsic reactivity of the substrate molecule. For instance, it is common to observe the selective oxidation of an unreactive region of a substrate molecule in an enzymatic reaction while much more reactive segments are left untouched. Enzymatic processes frequently achieve higher levels of selectivity which are not attainable by simple chemical means. Most enzyme catalyzed reactions are stereoselective, or in the choice of substrates, selective either in the type of chemical reactions performed and selective in the region of the molecule to be attacked. However, regioselectivity and stereoselectivity, in particular the formation of pure product enantiomers from achiral precursors, are aspects of enzymatic chemistry which are to be admired and imitated by synthetic chemists.

Biochemical selectivity is the result of the geometry of enzyme-substrate complexes, in which only certain substrates can fit in the enzyme and only certain points in the substrates are then in a position to be attacked. Geometric control was attained by using the reagentsubstrate complexes in which a relatively rigid reagent would direct the attack into a particular region of the substrate and this is called "biomimetic control". The term "biomimetic" has since come into wider use, generally referring to any aspect in which a chemical process imitates a biochemical reaction.

Certain supramolecular hosts, with their cavities have the potential to perform novel chemical transformations, mimicking the biochemical selectivity exhibited by enzymes. Binding of substrates to these supramolecular hosts involving intermolecular interactions of non covalent nature such as hydrogen bonding, van der Waals forces, etc. results in host guest complexation akin to biological receptors and substrates. The formation of such inclusion complexes involves molecular recognition capability of the supramolecular hosts. In fact molecular recognition involves both binding and selection of the substrate by the 
host. In addition if the host bears reactive functionalities, it results in the activation of the guest molecule to under go chemical transformation of the bound substrate, wherein the role played by the intermolecular forces is significant.

These supramolecular hosts have excited interest as enzyme models catalyzing chemical reactions involving the reversible formation of host-guest complexes. Cyclodextrins acquired prominence as supramolecular hosts as they modify the properties of the included molecules. Hence they are used in a variety of industrial applications, analytical techniques and as reaction mediator (Szejtli \& Osa, 1996).
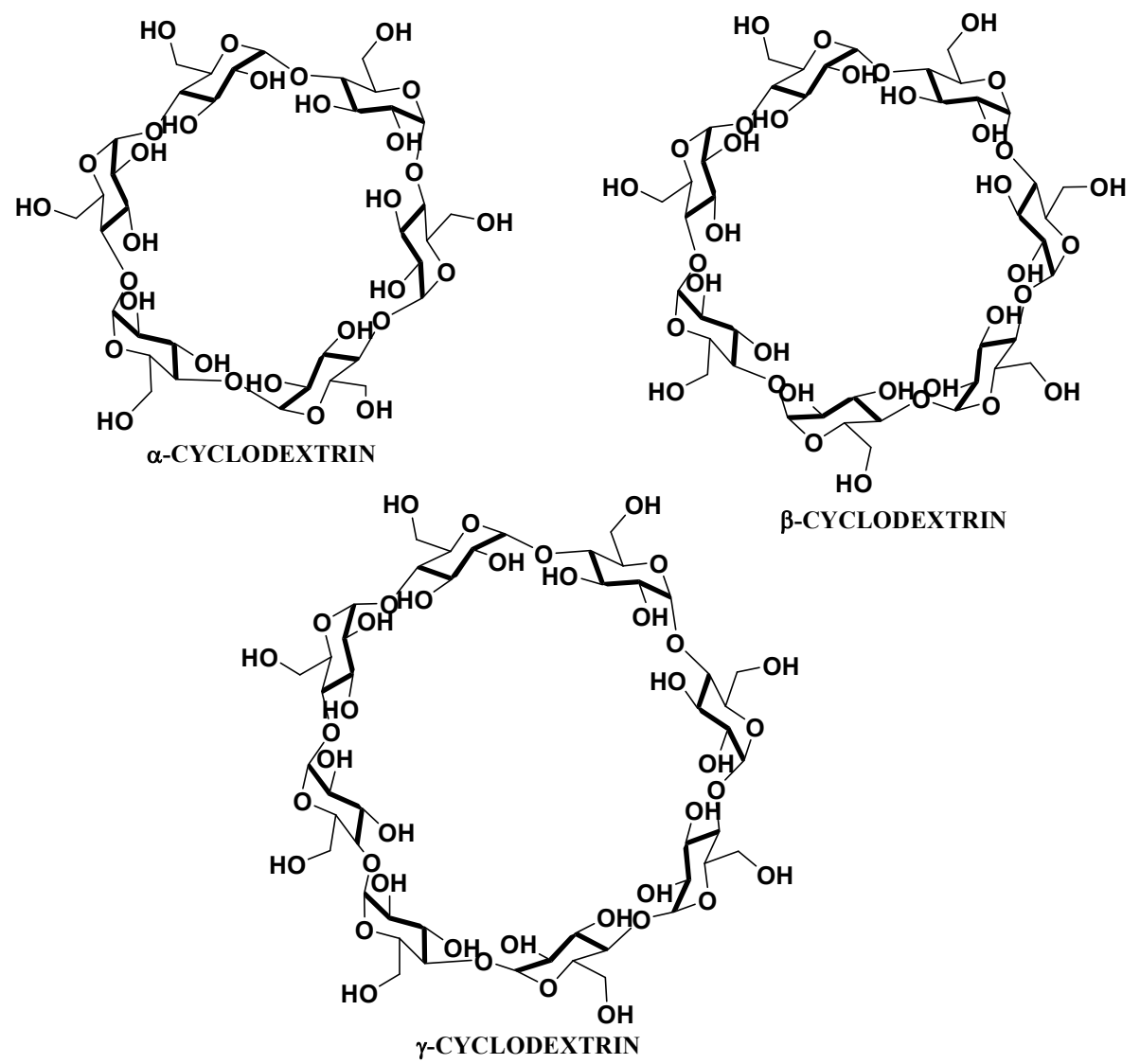

Structures of $\alpha, \beta$, and $\gamma-C D$

Cyclodextrins are produced from starch by the action of the enzyme cyclodextrin glucosyl trasferase (CGT). Cyclodextrins (CDs) are torus shaped cyclic oligosaccharides consisting mainly of $6(\alpha \mathrm{CD}), 7(\beta \mathrm{CD})$ and $8(\gamma \mathrm{CD}) \mathrm{D}$-glucose units. Each of the chiral glucose units is in the rigid ${ }^{4} \mathrm{C}_{1}$-chair conformation, giving the macrocycle the shape of a hollow truncated cone. The cone is formed by the carbon skeletons of the glucose units with glycosidic oxygen atoms in between. The primary hydroxyls of the glucose units are located at the narrow face of the cone and the secondary hydroxyls at the wider face. The primary hydroxyls on the 
narrow side of the cone can rotate to partially block the cavity. In contrast the secondary hydroxyls are attached by relatively rigid chains and as a consequence they can not rotate. The primary and secondary hydroxyls on the outside of the cyclodextrins make cyclodextrins water-soluble. Cyclodextrins are insoluble in most organic solvents.

Because of the relatively apolar cavity in comparison to the polar exterior, cyclodextrins can form inclusion compounds with hydrophobic guest molecules in aqueous solutions predominantly due to intermolecular interactions. In aqueous solution, the cyclodextrin cavity is occupied by water molecules in an energetically unfavorable polar-apolar association and the driving force for complex formation is the displacement of high energy water molecules by the hydrophobic guest molecule. The most important factor in complexation appears to be the "steric fit" ie., geometric compatibility between the host and the guest. However the stability of the resulting complexes varies with the size of both the guest and the host. The Stoichiometry of the guest to host in inclusion complexation is usually 1:1 in aqueous solution. Complexes can also be formed in DMF and DMSO, but they are less stable. However, in some cases complexation can also be formed in solid state.

Cyclodextrins with their hydrophobic cavities mimic enzymes in their capability in binding substrate selectively and catalyze the chemical reactions involving supramolecular catalysis. Cyclodextins became prominent as micro vessels for performing a variety of biomimetic synthetic reactions. Growing interest in different aspects of cyclodextrins resulted in steady increase in original research articles as well as reviews. Various methods that determine the host-guest complex formation include $X$-ray, fluorimetric measurements, NMR, circular dichroism, ESR, polarography, colorimetry, diffusion across semipermeable membranes and surface strain measurements. Among these methods X-ray and NMR have been established as important and reliable methods to determine molecular encapsulations. Some of the applications of CDs to attain higher selectivities in a variety of organic reactions including multi component synthesis of heterocycles are discussed.

In view of the significance attached to green chemistry and its relevance to the present day problem of global warming, the development of novel, simple, cleaner synthetic protocols is attracting attention in both academic and industrial research, resulting in an ever increasing number of publications or reports on this topic. Designing environ friendly synthetic strategies in water, minimizing the use of harmful, toxic, and flammable organic solvents and hazardous reagents/catalysts, is attaining the priority over other issues. Water has the status of universally acceptable solvent since it is economically affordable, readily available and nontoxic.

However the fundamental problem of performing organic reactions in water is that many organic substrates are hydrophobic and insoluble. These problems can be addressed if the reactions can be planned and executed by following biomimetic approaches through supramolecular catalysis, involving host-guest complexation, in aqueous medium.

In the present context and of particular interest are water soluble hosts with hydrophobic cavities, which can mimic the enzyme-receptor relationship (enzymatic biochemical reactions). Among various possibilities, cyclodextrins offer wider scope for designing and conducting organic reactions in hydrophobic environment following microencapsulation of the substrate molecules.

To overcome the drawbacks associated with the existing synthetic methodologies, many organic transformations were attempted successfully, by using cyclodextrin as a recyclable activator in aqueous medium. Presently, it is attempted to bring some of the very recent research reports, including certain unpublished results, into this article, focusing mainly on 
construction of heterocyclic moieties, utilizing cyclodextrin mediated biomimetic approach, in view of the significance attached to heterocyclic chemistry.

\section{Furanones}

Furan-2(5H)-ones are prominent structural motifs, widely present as a subunit in many natural products isolated from a variety of sources like algae, sponges, plants, insects and animals,. Literature survey indicates that butenolide substructure is present in more than 13,000 natural products and is the core structural unit responsible to induce a wide range of biological properties such as antimicrobial, antifungal, anti-viral HIV-1, anti-inflamatory, and anticancer (De Souza, 2005). It is found in many biologically active natural products such as sarcophine and rubrolide etc., which are isolated from Ritterela rubra, (Miao \& Andersen, 1991; Kotora \& Negishi, 1997) a colonial tunicate. It is also present in synthetic drug molecules like benfurodil hemisuccinate (Eucilat).

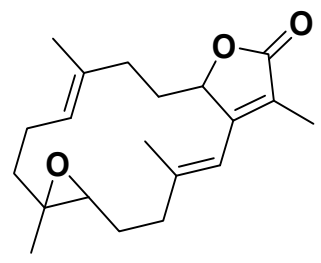

sarcophine

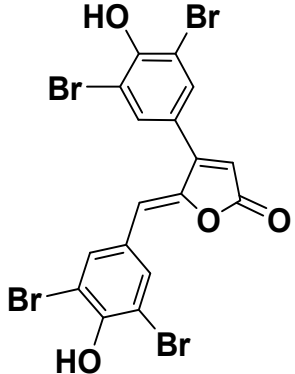

rubrolide<smiles>Cc1c(C(C)OC(=O)CCC(=O)O)oc2ccc(C3=CC(=O)OC3)cc12</smiles>

benfurodil hemisuccinate (Eucilat®)

The significant biological activity associated with butenolide synthon, attracted the attention of many researchers to develop numerous synthetic approaches for furan-2 $(5 \mathrm{H})$-one derivatives. The preparation of $2(5 \mathrm{H})$-furanone was also reported by refluxing furfural with hydrogen peroxide followed by oxidation resulting in a mixture of $2(3 \mathrm{H})$ and $2(5 \mathrm{H})$ furanones (Cao et al., 1996). Chunling Fu et al. described a new method for the synthesis of 4-iodofuran-2(5H)-ones, involving iodolactonisation of allenoates with molecular iodine (Fu $\& \mathrm{Ma}, 2005)$.

Sweeney et al. developed the first preparation of 3,4-bistributylstannyl 2(5H)-furanones by the reaction of TBS as well as THP protected butynoate with hexabutylditin in the presence of $\mathrm{PdCl}_{2}\left(\mathrm{PPh}_{3}\right)_{2}$ resulting in substituted acrylate intermediate, which upon treatment under a variety of conditions yielded desired furanone system (Hollingworth et al., 1996; Mabon et al., 1999 \& 2002) Mauro et al. reported the synthesis of furanone synthon via ring-closing metathesis catalyzed by the first generation Grubbs' catalyst (Bassetti et al., 2005). However these methodologies suffer from certain drawbacks like use of highly volatile flammable organic solvents, costly metal catalysts and multistep protocols. In view of these limitations, development of a novel eco-friendly approach to synthesize furanones is desirable.

Nageswar et al., during their efforts towards developing biomimetic organic synthetic protocols through supra molecular catalysis, utilizing recyclable activator like $\beta-C D$, reported a simple, one pot three component, methodology for the synthesis of $3,4,5-$ 
substituted furan-2(5H)-one derivatives from various substituted anilines, benzaldehydes and $\mathrm{DEAD}$ in water, in presence of $\beta-\mathrm{CD}$. This is the first report on the biomimetic synthesis of $3,4,5$ - substituted furan-2(5H)-ones, by the supra molecular catalysis of $\beta-\mathrm{CD}$, in water (Murthy et al., 2009).
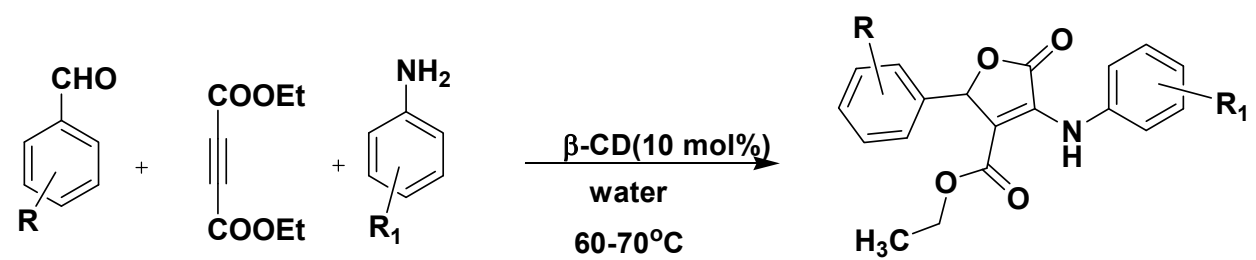

$$
\begin{aligned}
& \mathrm{R}=4-\mathrm{CH}_{3} ; 4-\mathrm{CH}_{2} \mathrm{CH}_{3} ; 4-\mathrm{OCH}_{2} \mathrm{Ph} ; 4-\mathrm{OCH}_{3} ; 4-\mathrm{OCH}_{2} \mathrm{CH}_{3} ; 4-\mathrm{Cl} ; \\
& \mathrm{R}_{1}=4-\mathrm{CH}_{3} ; 4-\mathrm{Cl} ; 4-\mathrm{F} ; 4-\mathrm{I} ; 4-\mathrm{nC}_{4} \mathrm{H}_{9} ; 3-\mathrm{Cl} ;
\end{aligned}
$$

Synthesis of $3,4,5$ - substituted furan-2(5H)-ones, in presence of $\beta$-CD as a supra molecular catalyst in water.

Initially, a model reaction was carried by the insitu formation of $\beta$-cyclodextrin complex of aniline in water at $50^{\circ} \mathrm{C}$, followed by the addition of diethylacetylenedicarboxylate and benzaldehyde while stirring at $60-70^{\circ} \mathrm{C}$ to obtain ethyl 2,5-dihydro-5-oxo-2-phenyl-4(phenylamino) furan-3-carboxylate in almost quantitative yield (85\%). No product formation was observed, when the reaction was conducted in neat or in presence of water even after prolonged reaction times. The scope of this novel and interesting transformation to synthesize 3, 4, 5-substituted furan-2(5H)-one derivatives with various substituted anilines and substituted aldehydes was studied by keeping diethylacetylenedicaboxylate as a common substrate. All the reactions were clean, and the products were obtained in high yields (78-88\%), with good amount of catalyst recovery. The results indicated that the substitution on the aromatic ring has a substantial role in governing the reactivity of the substrate as well as product yield. The reaction with electron donating groups like methyl, butyl on aniline gave good yield, where as in case of electron withdrawing groups, such as para-chloro and para-fluoro yields decreased. The reaction was observed to be sluggish with aliphatic amines, such as benzyl amines and n-alkyl amines. Structural identification of these products was established by spectral data. No lactone formation was observed in the absence of $\beta$-cyclodextrin, even after longer reaction times, establishing the role of $\beta$-CD. The formation of 3, 4, 5-substituted furan-2(5H)-ones, catalysed by $\beta$-CD was supported by ${ }^{1} \mathrm{H}$ NMR studies of the inclusion complex between aniline and $\beta-C D$. The hydrophobic environment in the cavity of $\beta-C D$ facilitates the completion of the reaction via aniline/diethylethylenedicarboxylate carbanion, which is stabilized by the primary and secondary $-\mathrm{OH}$ groups of $\beta-\mathrm{CD}$. This stabilized carbanion further reacts with aldehyde resulting in the formation of 3, 4, 5-substituted furan-2(5H)-one.

These reactions were conducted with a catalytic amount $(10 \mathrm{~mol} \%)$ of $\beta-\mathrm{CD}$ in water. Inclusion complex was prepared by taking $\beta-C D$ and aniline in 1:1 ratio for the purpose of NMR studies. NMR spectrum of $\beta-C D /$ aniline inclusion complex indicated upfield shift of aromatic protons as well as amine protons of aniline, due to the inclusion of aniline inside $\beta$ CD cavity. Apart from the upfield shift of aniline protons due to the incorporation of an aromatic ring inside the $\beta-C D$ cavity, the protons located in the hydrophobic cavity of $\beta-C D$ 
cavity (C3-H and $\mathrm{C} 5-\mathrm{H})$ were also shifted upfield due to magnetic anisotropy, caused by the aniline molecule (Grigoras \& Conduruta, 2006). $\beta-C D$ was recovered and reused for further runs of these reactions.

This biomimetic methodology for the synthesis of furanone derivatives involving CD as a supramolecular catalyst in aqueous medium may have wider applications in green chemistry protocols.

\section{Pyrroles}

The pyrrole structural motif widely occurs in nature and represents itself in many biologically important molecules such as porphyrins, alkaloids and coenzymes (Sundberg, 1996). Due to its application in many important areas, pyrrole skeleton has attracted the attention of many researchers globally. Paal-Knorr synthesis, Knorr pyrrole synthesis and Hantzsch synthesis were some of the classical approaches for the preparation of pyrroles. Though over the years numerous synthetic strategies were reported for the preparation of pyrrole derivatives (Shindo et al., 2007; Cyr et al., 2007; Binder \& Kirsch, 2006), most of them involve multistep synthetic processes, which reduce the overall yields. Even though recently a few one-step syntheses (Shiraishi et al., 1999) are reported for the preparation of pyrrroles, these suffer from several drawbacks such as use of toxic flammable organic solvents, costly transition metal catalysts and longer reaction times. To overcome these shortcomings associated with the existing methodologies, developing mild and environmentally benign synthetic protocols involving water as solvent for the synthesis of pyrrroles is desirable. Use of a recyclable catalyst as a part of green chemistry approach will be an additional advantage. Nageswar et al. during their efforts towards developing novel $\beta$-cyclodextrin-promoted synthetic strategies attempted for the first time simple versatile biomimetic approach for the synthesis of substituted pyrroles from readily available building blocks in aqueous medium under supramolecular catalysis (Murthy et al., 2009).

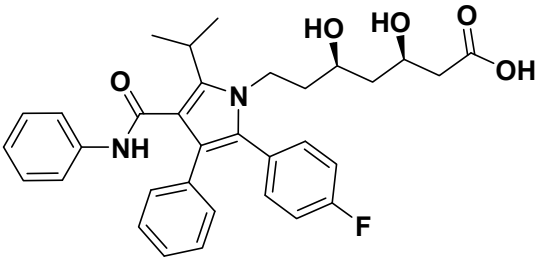

Atorvastatin

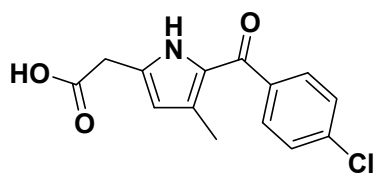

Zomepirac<smiles>CN(C)CCc1c[nH]c2ccc(O)cc12</smiles>

Bufotenin

Initially, phenacyl bromide is solubilised in aqueous solution containing $\beta-C D$ at $50^{\circ} \mathrm{C}$. To this $\beta$-CD-phenacyl bromide complex was added pentane-2, 4-dione followed by aniline. The entire reaction mixture was stirred at $60^{\circ} \mathrm{C}-70^{\circ} \mathrm{C}$ till the reaction goes for completion, giving the 1, 2, 3, 5-substituted pyrrole in excellent yield (86\%). To study the scope of this interesting one pot three component biomimetic approach for the preparation of pyrrole derivatives, several reactions were carried out under similar reaction conditions, changing the amine component. 4-Methyl; 4-methoxy; 3, 4-dimethoxy; 4-chloro; 4-fluoro; 4-n butyl anilines, benzyl amine, 3-methoxy benzyl amine and 3-bromo benzyl amine were also utilized as reactants. 


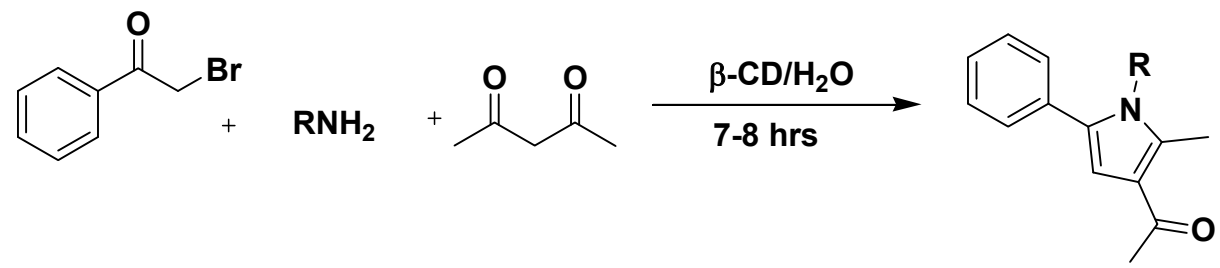
$\mathbf{R}=\mathbf{P h}$; 4-Chloro phenyl;4-Methyl phenyl; 4-Fluoro phenyl; 4-Methoxy phenyl; 3,4-Dimethoxyphenyl; 4-n-Butylphenyl;Benzyl;3-Bromo benzyl; 3-Methoxy benzyl; 2,6-Diethyl phenyl

Synthesis of substituted pyrrole derivatives by one-pot three component approach using $\beta$-cyclodextrin as a recyclable catalyst:

It was observed that aromatic amines with electron-donating groups in $p$-position gave excellent yields, where as electron- withdrawing groups in $p$-position gave relatively reduced yields. The reactions with aliphatic amines resulted in still lower yields.

The role of $\beta$-cyclodextrin in these reactions was to solubilise and activate phenacyl bromides through hydrogen-bonding interactions, thereby promoting the reaction with pentane-2, 4-dione to complete the reaction sequence with an amine. Reaction was not observed in the absence of $\beta-C D$. $\beta$-CD was recovered and used to run subsequent cycles of the reaction. A reaction mechanism via the formation of $\beta-\mathrm{CD} /$ phenacyl bromide complex was suggested, which was further supported by the preparation and characterization studies on $\beta-\mathrm{CD} /$ phenacyl bromide inclusion complex, which was obtained by taking $\beta$ cyclodextrin and phenacyl bromide in equimolar quantities. ${ }^{1} \mathrm{H}-\mathrm{NMR}$ studies of the inclusion complex between $\beta-\mathrm{CD}$ and phenacyl bromide indicated the upfield shift of $\mathrm{H}-\mathrm{C}(3)$ and $\mathrm{H}-$ $\mathrm{C}(5)$ of $\beta-\mathrm{CD}$.

This novel, simple, and environmentally benign methodology following the biomimetic approach, reported for the first time involving $\beta$-cyclodextrin as a recyclable activator by Nageswar et al., may be a useful application to pyrrole chemistry.

\section{Oxindoles}

Oxindole chemistry has been extensively investigated, as it is an intermediary system between indole and isatin, two prominent structural frame works in organic chemistry. Isatin was converted to oxindole via dioxindole, first by Baeyer, establishing the relationship between the compounds. Reduction of isatin can be effected with a wide range of reducing agents such as sodium amalgam, zinc in acetic acid or zinc in hydrochloric acid or nickel catalyst. Oxidation of indoles and its derivatives by various oxidizing agents such as $\mathrm{KMnO}_{4}, \mathrm{HNO}_{3}, \mathrm{H}_{2} \mathrm{SO}_{4}$, etc. result in oxindole skeleton.<smiles>O=C1Nc2ccccc2C1=O</smiles>

isatin<smiles>O=C1Nc2ccccc2C1O</smiles>

dioxindole<smiles>O=C1Cc2ccccc2N1</smiles>

oxindole 
The Baeyer's first total synthesis of oxindole from phenyl acetic acid via 2-nitrophenyl acetic acid was further modified and improved by different researchers such as Hahn, Hinsberg as well as Brunnes.

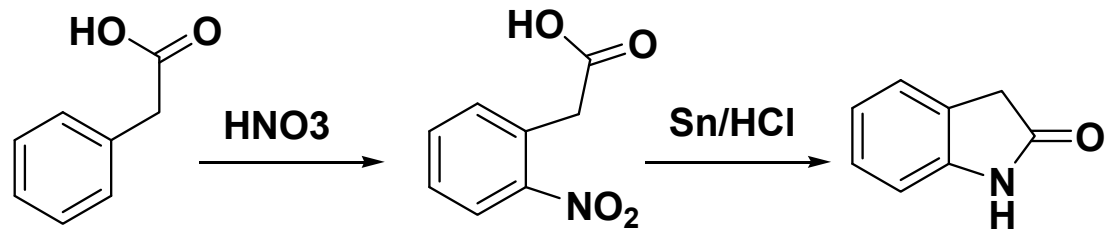

Hinsberg obtained oxindole by the reaction of aromatic amine with sodium bisulfite addition compound of glyoxal, where as Brunner prepared oxindoles by reacting an acylphenyl hydrazine in presence of alkaline reagents resulting in elimination of $\mathrm{NH}_{3}$. In Stolle's synthesis of oxindole, a-halo acetanilide is heated with anhydrous $\mathrm{AlCl}_{3}$ resulting in the cyclisation with elimination of $\mathrm{HCl}$.

Recently a series of substituted oxindole derivatives were synthesized and evaluated for growth harmone releasing activity (Tokunaga et al., 2001). Gallagher et al., synthesized and reported 4-[2-(Di-n-propyl amino) ethyl]-2(3H)-indolone (SK\&F 101468) as a potent and selective prejunctional dopamine receptor agonist. (Gallagher et al., 1985). A series of N-(3piperidinyl)-2-indolines were synthesized and evaluated as a new structural class of nociceptin receptor (NOP) ligands (Zaveri et al., 2004). Spirotrypro statins A\&B, isolated from the fermentation broth of Aspergillus fumigatus exhibited cell cycle inhibition and some of their biologically promising analogues were also reported (Edmondson et al., 1999). The spirooxindole is a prominent structural component present in a number of natural products, such as coerules-cine, elacomine, horsfiline, welwitindolinone A, spirotryprostatin A, alstonisine, and surugatoxin. These compounds exhibit potent cytotoxic activity and are also known as estrogen-receptor modulators, h5-HT6 serotonin receptors, oxytocin antagonists, and antiproliferative agents. Due to their significant biological activity several synthetic methodologies have been developed for the construction of spirooxindole system. In view of the growing focus on environ friendly processes, Rao et al. revisited the synthesis of spirooxindoles by utilizing the supra molecular catalytic biomimetic approach (Sridhar et al., 2009).

Literature reports on the synthesis of spirooxindole described so far by the three component condensation reaction of isatin, malononitrile or methyl cyanoacetate, and 1, 3-dicarbonyl compounds have certain limitations as they involve the use of hazardous organic solvents, acidic or basic conditions, transition metal catalysts, surfactants, and microwave irradiation. Consequently the development of environ-friendly approaches for these spirooxindoles derivatives under neutral conditions using a recyclable activator in water is desirable.

A. Rao et al. explored the aqueous-phase synthesis of spirooxindole derivatives by the three component reaction of isatin, malononitrile, and dimedone under neutral conditions catalysed by $\beta$-cyclodextrin.

In general, these reactions were conducted via the formation of $\beta-C D$ complex of isatin in water. This was followed by the successive addition of malononitrile and dimedone, and stirring at $60^{\circ} \mathrm{C}$. The corresponding spirooxindole derivatives were obtained in excellent yields $(84 \%-91 \%)$ after $4-6 \mathrm{~h}$. This simple methodology reported by Rao et al. was compatible with several substituted isatins having different functionalities such as bromo, 
methyl, nitro, phenyl, and benzyl groups. It was observed that reaction of methyl cyanoacetate with isatin and dimedone under similar conditions resulted in the expected product in very good yields. All these reactions proceeded efficiently without any byproduct formation. $\beta$-cyclodextrin can be easily recovered and reused.<smiles></smiles><smiles></smiles>

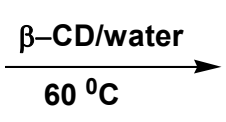<smiles></smiles>

$$
\begin{aligned}
& \mathrm{R}=\mathrm{H}, 4-\mathrm{Br}, 6-\mathrm{Br}, 5-\mathrm{CH}_{3}, 5-\mathrm{NO}_{2} \\
& \mathbf{R}^{1}=\mathrm{CH}_{3}, \mathrm{CH}_{2} \mathrm{Ph}, \mathrm{Ph} \\
& \mathbf{R}^{2}=\mathrm{CN}, \mathrm{COOMe}
\end{aligned}
$$

$\beta$-CD-catalyzed one-pot multi-component synthesis of spirooxindoles:

The scope of this methodology has been extended to the reaction of 4-hydroxy coumarin and barbituric acid under similar reaction conditions to obtain spirooxindole derivatives in impressive yields. Isolation of $\beta$-CD-isatin complex confirmed the complexation process. It was observed from ${ }^{1} \mathrm{H}$ NMR studies $\left(\mathrm{D}_{2} \mathrm{O}\right)$ of $\beta$-CD, $\beta$-CD-isatin complex, and freeze-dried reaction mixture of isatin-malononitrile-dimedone, that there was an up-field shift of $\mathrm{H} 3$ and $\mathrm{H} 5$ protons of cyclodextrin in the $\beta$-CD-isatin complex as compared to $\beta$ - CD.This proves the formation of an inclusion complex of isatin with $\beta$-CD from the secondary side of cyclodextrin. Authors observed that the spectra of the reaction mixture of the $\beta$-CD-isatin complex after the addition of malononitrile and dimedone after $2 \mathrm{~h}$, showed an upfield shift of the CD H6 proton. This confirms that the reaction proceeded by the complexation of malononitrile and dimedone from the primary side of cyclodextrin and that isatin is ideally placed for the condensation with malononitrile and dimedone in the cyclodextrin cavity.

In the absence of cyclodextrin, the reaction was observed to proceed in lower yields even after longer reaction times. During complexation with $\beta-C D$ the reactivity of the keto group of isatin increased due to intermolecular hydrogen bonding with the CD-hydroxyl groups. This facilitated the Knoevenagel condensation with malononitrile to form an isatylidene malononitrile, which undergoes the established sequence of reactions successively such as Michael addition of dimedone, and the cycloaddition of hydroxyl group to the cyano moiety to form the desired spirooxindole derivatives.

This neutral aqueous phase one-pot three-component biomimetic synthesis of various spirooxindole derivatives by the reaction of isatin and 1,3-dicarbonyl compounds, is an impressive addition to green chemistry.

B. a-Hydroxyphosphonates are prominent class of biologically active compounds as well as useful reactive intermediates (Maryanoff \& Reitz, 1989). In view of significant biological importance associated with a-hydroxy phophonates, this synthon has attracted enhanced research interest. These are extensively used in pharmaceutical applications such as enzyme inhibitors of renin, HIV protease and EPSP synthase (Patel et al., 1995). They also exhibited potential biological activities, such as antibacterial, antiviral, anti-inflammatory, laxative, growth hormonal, and anticancer activities (Stowasser et al., 1992). They are also 
used in the synthesis of 1, 2-diketones from acid chlorides, a-ketophosphonates and $\alpha$ aminophosponates (Kaboudin, 2003; Firouzabadi et al., 2004; Iorga et al., 1999).

Generally the synthesis of a-hydroxy phosphonates involve the reaction of aldehydes or ketones with dialkyl or trialkyl phosphites in the presence of acidic or basic catalysts. aHydroxy phosphonates can also be synthesised from Tris(trimethylsilyl) phosphite but it requires elevated temperature under anhydrous reaction conditions. However, these methodologies suffer from several drawbacks such as the use of hazardous solvents, acidic conditions and metal catalysts. Consequently, the development of environfriendly biomimetic approach under neutral conditions for the synthesis of a-hydroxy phosphonates is desirable. Aqueous phase organic synthesis has recently become the focus in the development of green synthetic protocols, and it can be made more sophisticated if they can be performed under supramolecular catalysis.

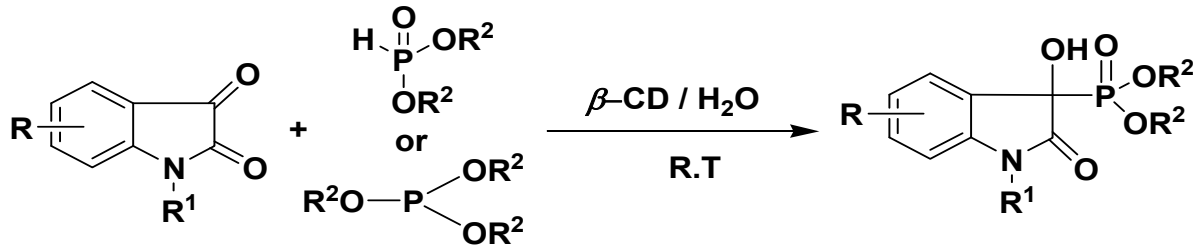

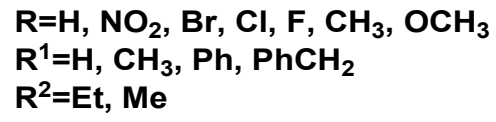

\section{$\beta$-CD catalyzed one-pot multi-component synthesis of $\mathbf{a}^{1}$-oxindole-a-hydroxy phosphonates}

Due to the various biological activities associated with various oxindole derivatives, and ahydroxy phosphonates, Nageswar et al. have attempted for the first time a simple aqueous phase biomimetic synthesis of $\alpha^{1}$-oxindole- $\alpha$-hydroxy phosphonates by the reaction of isatin derivatives with dialkyl or trialkyl phosphites under neutral conditions in presence of $\beta$ cyclodextrin, as a supramolecular catalyst (Shankar et al., 2010).

Initially a reaction was conducted by the insitu formation of the $\beta$-CD complex of the isatin in water followed by the addition of dialkyl or trialkyl phosphite. The reaction mixture was stirred at room temperature to give the corresponding $\alpha^{1}$-oxindole-a-hydroxy phosphonates in impressive yields (86-94\%). Scope of this reaction was extended to involve various substituted isatin. Reactions performed under similar conditions proceeded efficiently without the need of any metal or acid catalyst. Even though the reactions occurred in presence of $a-C D$ and $\gamma-C D$, with lesser yields, inexpensive and easily accessible $\beta-C D$ was selected as the mediator.Different substituted oxindoles synthesised by this simple and practicable methodology were characterized by their spectral data.

The catalytic efficiency of cyclodextrins for these reactions was established as no reaction was observed in the absence of cyclodextrin. Evidence for complexation between the isatin and cyclodextrin was deduced from NMR studies. A comparison of the ${ }^{1} \mathrm{H}$ NMR spectra $\left(\mathrm{D}_{2} \mathrm{O}\right)$ of $\beta-\mathrm{CD}, \beta-\mathrm{CD}$ : isatin complex revealed, the upfield shift of $\mathrm{H} 3$ and $\mathrm{H} 5$ protons of cyclodextrin in the $\beta-\mathrm{CD}$ : isatin complex as compared to $\beta$-CD. This confirmed the formation of an inclusion complex of isatin with $\beta$-CD. During complex phenomenon the keto group of isatin will be activated due to the inter molecular hydrogen bonding between CD-hydroxyl 
groups and isatin carbonyl, which facilitates the addition of phosphite. No by product formation was observed and the $\beta-\mathrm{CD}$ was recovered for further runs of these reactions.

Thus authors developed for the first time a simple neutral aqueous phase biomimetic synthetic protocol for the preparation of various $a^{1}$-oxindole-a-hydroxy phosphonates by the reaction of the corresponding isatins with dialkyl or trialkyl phosphites in the presence of $\beta$-cyclodextrin. This novel methodology will be an useful addition to indole chemistry.

\section{Thiazoles}

Thiazoles are a prominent class of $\mathrm{N}$-containing heterocyclic compounds of immense interest to medicinal and industrial chemists as these play a significant role in nature and have wider applications in agricultural and medicinal chemistry. For example the thiazole in vitamin B serves as an electron sink, and its coenzyme form is important for the decarboxylation of a-keto acids and is present in various natural products and herbicides. This important and useful structural motif has found application in drug development, as these exhibit diverse biological activities such as anti-glutamate, anti-Parkinson (Benazzouz et al., 1995), anti-microbial (Palmer et al., 1971), anthelmintic, anti-inflammatory (Haviv et al., 1988), anti-hyperlipidemic, anti-hypertension (Patt et al., 1992), and anti-oxidant properties as well as inhibition of enzymes such as acetylcholine esterase (Nagel et al., 1995), aldose reductase (Mylari et al., 1991), lipoxygenase (Hadjipavlou-Litina \& Geronikaki,1998), ATPase (Sohn et al., 1999), and HCV helicase (phoon et al., 2001). Aminothiazoles are reported as a new class of adenosine receptor antagonists and ligands of estrogen receptors.<smiles>Cc1ccc(Oc2ccccc2-c2csc(NC3=NCCCN3)n2)c(C)c1</smiles>

\section{Abafungin \\ Broadspectrum Anti-fungal agent}<smiles>Nc1ccc(S(=O)(=O)Nc2nccs2)cc1</smiles><smiles>Cc1cnc(NC(=O)C2=C(O)c3ccccc3S(=O)(=O)N2C)s1</smiles>

\section{Meloxicam \\ Non-steroidal \\ Anti-inflammatory Drug}

Several research groups worked extensively on thiazoles to develop various synthetic methodologies. Among these Hantzsch synthesis is the most widely used and applied, which involves the reaction of a-halo ketone or aldehyde with thioamide

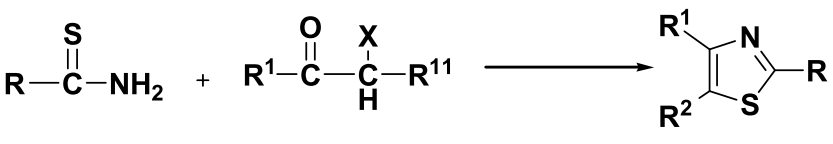

\section{$\mathrm{R}=\mathrm{NH}_{2}, \mathrm{SH}, \mathrm{S}-\mathrm{NH}_{4} \quad \mathrm{X}=\mathrm{Cl}, \mathrm{Br}, \mathrm{I}$}

The scope for a wider selection of readily available/accessible reactants resulted in broader applicability of Hantzsch thiazole synthesis, which had fewer limitations. With a proper choice of reactants, thiazoles with alkyl, aryl or heterocyclic moieties attached to any of the three carbons of the thiazole nucleus can be prepared in this methodology. Thio amide can 
also be replaced by thiourea or ammonium dithiocarbamate, or dithiocarbamate, or dithiocarbamic acid or mono thio-carbamic acid or it's o-esters. Based on Hantzsch concept, some newer methods, such as cycloaddition of tosylmethyl isocyanide to thione derivatives (Bergstrom et al., 1994), oxidation of thiazoline and thiazolidine ring systems (Martin \& $\mathrm{Hu}$, 1999), the Ugi reaction (Kazmaier \& Ackermann, 2005) and others (Mustafa et al., 2004), have been developed.

Other methodologies developed include Pd-mediated coupling process (Sapountzis et al., 2005; Lipshutz et al., 2004; Nicolaou et al., 1999), nucleophilic reactions of Lithiothiazoles (Dondoni, 1998), solid supported synthesis to generate small organic molecule libraries (Kazzouli et al., 2002) and solution phase preparation of 2-aminothiazole combinatorial libraries (Bailey et al., 1996).

Many of these synthetic methods involve the use of hazardous organic solvents, high temperatures, longer reaction times or lower yields. To overcome some of these limitations and while developing biomimetic approaches through supramolecular catalysis using cyclodextrin as a recyclable catalyst in aqueous phase, Rao et al. reported three different protocols for the synthesis of thiazole derivatives.

A. Different $\beta$-ketoesters were reacted with thiourea in presence of $\beta$-CD and NBS in water at $50{ }^{\circ} \mathrm{C}$ to obtain 4-substituted -2-amino-thiazole-5-carboxylates in excellent yields. In general these reactions were carried out by the insitu formation of $\beta$-CD complex of $\beta$ ketoesters in water at $50{ }^{\circ} \mathrm{C}$, followed by the addition of $\mathrm{N}$-bromo succinimide and thiourea. The reaction mixture was stirred for 1-2 hrs, and worked out to isolate expected products. In these reactions, the treatment of $\beta$-ketoesters with NBS may form a-bromo- $\beta$-keto esters as intermediates, which undergo cyclization with thiourea resulting in the thiazole derivatives. These reactions are simple, straight forward and high yielding protocols. The role of $\beta-\mathrm{CD}$ is to dissolve and activate the $\beta$-ketoester molecule through hydrogen-bonding, to promote the reaction. Solubility problems, longer reaction hours, low yields or mixture of products were the drawbacks when $\beta$ $\mathrm{CD}$ was not used. This efficient biomimetic process is a valuable addition for green chemistry, and may find wide spread applications (Narender et al., 2007).

B. Various phenyl tosylates were reacted with thiourea in presence of $\beta-C D$ in water at room temperature to get 2, 4-disubstituted thiazoles in very good yields. In general, the reaction was carried out by the insitu formation of the $\beta$-CD complex of $\beta$-keto tosylate in water followed by the addition of thioamide/thiourea and stirring for $1-3 \mathrm{~h}$ at room temperature to give the corresponding thiazole or aminothiazole derivatives. Several examples were prepared, illustrating this simple and practical methodology. These reactions proceeded smoothly without the formation of any by products. $\beta-C D$ can be easily recovered and reused. Solubility problems, longer reaction hours, lower yields, or mixture of products were the drawbacks when $\beta-C D$ was not used. This simple, practicable biomimetic approach is an useful addition for green chemistry. The formation of the inclusion complex between $\beta$-ketotosylate molecule and $\beta-\mathrm{CD}$ results in chemical shift changes of cyclodextrin. The inclusion of an aromatic guest into the cyclodextrin cavity results in upfield shifts of the H-3 and H-5 of cyclodextrin, due to the ring-current effect of the aromatic ring (Demarco \& Thakkar, 1970). Study of ${ }^{1} \mathrm{H}$ NMR (DMSO) of the $\beta-C D, \beta-C D$-phenacyl tosylate complex, and freeze-dried reaction mixtures of $\beta$-CDphenacyl tosylate-thiourea indicated up field shift of $\mathrm{H}-3$ and $\mathrm{H}-5$ protons in the complex as well as in the reaction mass after $30 \mathrm{~min}$. Hydrogen bonding of the tosyl group with cyclodextrin hydroxyl functionality facilitated the attack by the substrate nucleophile 
initiating the reaction to take place. Significance of this procedure are operational simplicity, excellent yields, and recyclability of the catalyst (Kumar et al., 2007).

C. Rao et al. reported the biomimetic synthesis of thiazole derivatives by reacting thioamide/thiourea and various substituted phenacyl bromides in presence of $\beta$ cyclodextrin in aqueous medium at $50{ }^{\circ} \mathrm{C}$ with no other additive. In general the reactions were carried out by the insitu formation the $\beta$-cyclodextrin complex of phenacyl bromide derivatives in water followed by the addition of thiourea or thioamide to give the corresponding thiazoles and aminothiazoles. The reactions were performed smoothly without the formation of any byproducts and the expected new products were obtained in impressive yields. These thiazole derivatives were identified with the help of various analytical techniques. The role of $\mathrm{CD}$ in these reactions appears to be to solubilise phenacyl bromide derivatives by complexing them and activating the molecules to promote the reaction with thioamide/thiourea. In the absence of cyclodextrin the reaction has lot of drawbacks such as solubility problems, longer reaction times and very low yields. This novel methodology overcomes all these limitations, apart from formation of unwanted byproducts and will be an interesting addition to biomimetic chemistry.

\section{Selenazoles}

Selenazoles have been widely studied as reactive synthons as well as for their potential biological activity. Among them 1, 3- selenazoles are of pharmacological importance due to their cancerostatic and antibiotic activity (Goldstein et al., 1990; Srivastava \& Robins, 1983). The C-glycosyl selenazofurin is an important example for antibacterial activity. 2-Amino-1,3selenazoles are good superoxide anion-scavengers. Various synthetic methodologies have been developed for the selenium-containing heterocyclic compounds due to their interesting applications (Back, 1999; Wirth, 2000). These selenazoles have been synthesised mainly by the application of Hantzsch procedure.The existing protocols have a number of limitations (Koketsu et al., 2006, 2005 \& 2004) such as the use of inert atmosphere, anhydrous organic solvents, basic conditions, longer reaction times, and lower yields. Selenourea, an important reactant in these methods, is an air and light sensitive compound. In view of these drawbacks there is a need to develop a mild and ecofriendly biomimetic methodology for these important compounds, using a recyclable supramolecular host.<smiles>[R]c1cccc(-c2csc(N)n2)c1</smiles>

$\mathrm{R}=\mathrm{H}, \mathrm{Me}, \mathrm{Br}, \mathrm{I}, \mathrm{MeO}, \mathrm{NO}_{2}$<smiles>CCOC(=O)C(Br)C(C)=[18O]</smiles>
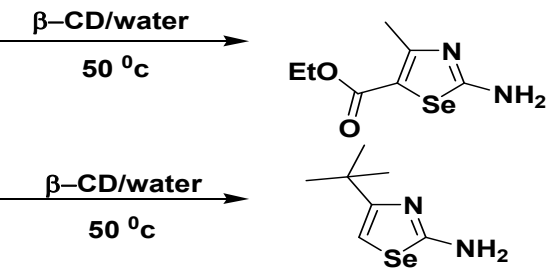

Synthesis of Selenazoles in Water in the Presence of $\beta$-Cyclodextrin 
To overcome some of the limitations in the existing methodologies, Rama rao et al., developed simple biomimetic approach through supramolecular catalysis, for the synthesis of 2-amino-1, 3-selenazoles from a-bromoketones, and selenourea in the presence of $\beta$ cyclodextrin (Narender et al., 2007). In this investigation the reactions were conducted by the in situ formation of $\beta$-cyclodextrin complex of a-bromoketone in water at $50{ }^{\circ} \mathrm{C}$, followed by the addition of selenourea. The reaction mixture was stirred to give the corresponding selenazoles in quantitative yields (86-95\%). During the study, it was observed that the aromatic a-bromoketones (substituted phenacyl bromides) gave comparatively higher yields than those with aliphatic a-bromoketones. For example, Ethyl 2-amino-4methyl-1, 3-selenazole-5-carboxylate was obtained in $87 \%$ yield whereas 4(4methoxyphenyl)-2-amino-1, 3-selenazole-5-carboxylate was produced in 95\% yield. The reactions proceeded without the formation of any unwanted side products. The products were characterized by spectroscopic data. $\beta$-Cyclodextrin was recovered and used for further runs. Even though these reactions take place in presence of a-cyclodextrin (a-CD), $\beta$ $\mathrm{CD}$ was used as the activator as it is inexpensive and easily available. Solubility problems, longer reaction times, lower yields were some of the drawbacks observed, when $\beta$ cyclodextrin was not used. When only catalytic amount of $\beta$-CD $(0.1 \mathrm{mmol}$ per mole of the substrate) was used it had no impact on the reaction, since the yields of the product obtained were the same as observed in the absence of $\beta$-CD. The study indicated the substantial role of cyclodextrin as a supra molecular catalyst in these reactions. It was also established through ${ }^{1} \mathrm{H}$ NMR studies with phenacyl bromide as a representative example. Upfield shift of $\mathrm{H} 3$ and $\mathrm{H} 5$ protons of $\beta$-CD in the case of $\beta$-CD-PB complex as compared to $\beta$-CD was explained as due to the screening effect of the phenyl ring of phenacyl bromide included in the hydrophobic cavity of $\beta-C D$. The upfield shifts prove the formation of an inclusion complex of phenacyl bromide with $\beta$-CD (D'Souza \&Lipkowitz, 1998). With the addition of selenourea (after 20 and $40 \mathrm{~min}$ ), there was a further upfield shift of the $\mathrm{H} 3$ and $\mathrm{H} 5$ protons. This increase in the upfield character of $\mathrm{H} 3$ and $\mathrm{H} 5$ protons of $\beta$-CD in $\beta$-CDphenacylbromide complex was explained as the enhanced aromatic nature in the phenyl selenazole derivative. Thus, in this investigation, $\beta$-cyclodextrin appears to solubilise and activate phenacyl bromides and promote the reaction.

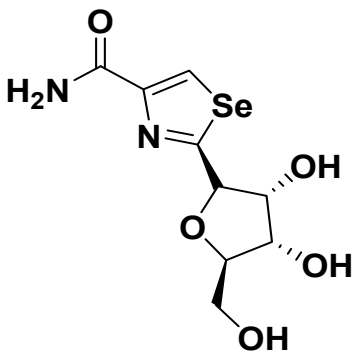

Selenazofurin

Thus the authors have investigated for the first time that selenazole formation can be promoted by $\beta$-cyclodextrin in water, making this methodology as a useful addition to the cyclodextrin mediated biomimetic organic synthesis. 


\section{Quinoline derivatives}

Quinolines are N-containing heterocycles found in many natural products such as quinine, camptothecin etc, and several other drug molecules. They exhibit remarkable biological activities like anti-malarial, anti-inflammatory, anti-asthmatic, anti-bacterial, antihypertensive, anti-tubercular, anti-alzheimer, anti-HIV, and anti-cancer (Michael, 2007; Suresh et al., 2009). In addition, quinolines are valuable synthons, used for the preparation of nano and mesostructures with enhanced electronic and photonic properties (Zhang et al., 1999; Jenekhe et al., 2001). Therefore, quinoline ring system developed as an important target for extensive research in synthetic organic chemistry.<smiles>C=C[C@H]1CN2CC[C@H]1C[C@@H]2[C@H](O)c1ccnc2ccc(OC)cc12</smiles>

Quinine<smiles>CC[C@@]1(O)C(=O)OCc2c1cc1n(c2=O)Cc2cc3ccccc3nc2-1</smiles>

Camptothecin<smiles>OC(c1cc(C(F)(F)F)nc2c(C(F)(F)F)cccc12)C1CCCCN1</smiles>

Mefloquine

Skraup, Combes, Friedlander, Doebner-VonMiller syntheses, are some of the well known methodologies for the synthesis of quinoline structural frames. Many new synthetic protocols are being reported frequently using various starting materials. Recently Gabriele (Gabriele et al., 2007) synthesized substituted quinolines from 2-aminoaryl ketones by initial reaction with Grignard reagent and further cyclization in presence of $\mathrm{Cu} / \mathrm{Pd}$ catalysts. Francis (Francis et al., 2008) reported quinoline synthesis from 2-aminobenzyl alcohol and a variety of ketones catalysed by ruthenium catalysts. Xin-Yuan (Xin-Yuan et al., 2007) introduced gold catalysed quinoline synthesis under microwave-assisted conditions. Lewis acids(Hu et al., 2003; McNaughton \& Miller, 2003; Zhang \& Wu, 2007), Bronsted acids(Muscia et al., 2006), molecular iodine(Wu et al., 2006), proline (Jiang et al., 2008), ionic liquids (Dabiri et al., 2008) and transition metals (Martinez et al., 2007;Gabriele et al., 2007; Vieira \&Alper, 2007; Cho \& Ren, 2007) were some of the catalysts involved in different synthetic protocols for quinoline structural motif. However many of the aforementioned reactions require strong acids or bases, toxic flammable organic solvents, or hazardous/ expensive catalysts and elevated temperatures. These reaction conditions are also tedious and yields are low, even after prolonged reaction times.

In view of these drawbacks, it is desirable to attempt the synthesis of these bioactive molecular frame works, by environ friendly biomimetic synthetic protocols of simple nature. There are few reports (Taylor \& Heindel, 1967; Hendrickson et al., 1964; James \& Fanta, 1962; Bryce et al., 1983) in literature especially for the preparation of 4-substituted quinolone-2, 3-dicarboxylates. Taylor synthesized quinoline-2, 3-dicarboxylates from 2aminobenzophenone and dimethyl acetylenedicarboxylate in benzene under reflux conditions. As 2-amino acetophenone did not react with DMAD in one pot, basic conditions (NaOMe in anhydrous $\mathrm{MeOH}$ ) were used for the enamine adduct to cyclise in $26 \mathrm{hrs}$. 
<smiles>[R]C(=O)c1cc([R4])c([R4])cc1N</smiles>

$\mathrm{R}=\mathrm{H}, \mathrm{Me}, \mathrm{Ph}, 2-\mathrm{Cl}-\mathrm{C}_{6} \mathrm{H}_{4} ; \mathrm{R}^{1}=\mathrm{H}, \mathrm{Br}, \mathrm{OMe} ; \mathrm{R}^{2}=\mathrm{H}, \mathrm{Cl}, \mathrm{OMe} ; \mathrm{R}^{3}=\mathrm{Me}$, Et.

\section{Synthesis of 4-substituted quinoline-2, 3-dicarboxylates by using $\beta$-cyclodextrin under neutral conditions in aqueous medium:}

While exploring biomimetic approaches through supramolecular catalysis in investigating various organic transformations, Nageswar et al. attempted to prepare several substituted quinolone-2,3-dicarboxylates using $\beta$-cyclodextrin $(\beta-C D)$ as a supra molecular catalyst in aqueous medium (Madhav et al., 2010).

Initially the reaction between 2-aminobenzophenone and dimethyl acetylenedicarboxylate was carried out in water catalyzed by $\beta$-CD to obtain dimethyl 4-phenylquinoline-2, 3dicarboxylate in one pot at $75{ }^{\circ} \mathrm{C}$ in $85 \%$ yield. The desired quinoline derivatives were obtained in an almost quantitative yields, in shorter reaction times. The reaction did not proceed in the absence of $\beta-C D$. Scope of the reaction was extended to include various 2amino carbonyl compounds as substrates, and all these reactions proceeded to give the expected quinoline compounds in very good yields. Only trace of the product was isolated after longer reaction times, when 5-nitro-2-aminobenzophenone was used as a reactant. These reactions were also extended to cover diethyl acetylenedicarboxylate. Di (tert-butyl) acetylenedicarboxylate did not react under similar experimental conditions.

In general, the reactions carried out were simple, clean, and efficient. It was observed that the substitution played a significant role in governing the reactivity of the substrate. Experiments indicated that the reactions with 2-aminoacetophenone resulted in higher yields of the quinoline derivatives when compared to the reactions with 2-amino benzophenones. Among the 2-aminoacetophenones, unsubstituted 2-aminoacetophenone afforded good yield, and 4, 5-methylenedioxy-2-aminoacetophenone resulted in lower yield. Reactions with substituted 2-aminobenzophenones resulted in lower yields compared to unsubstituted 2-aminobenzophenone. Reactions with dimethyl acetylenedicarboxylate (DMAD) resulted in higher yields when compared to those with diethyl acetylenedicarboxylate (DEAD).

${ }^{1} \mathrm{H}-\mathrm{NMR}$ studies supported the formation of complexation between 2-aminobenzophenone and $\beta$-cyclodextrin. The reactions were carried out with 0.5 equiv. of $\beta$-CD, and detailed investigation of complexation studies were undertaken with $\beta$-CD/2-aminobenzophenone in 1:1 ratio as a representative example. Comparative study of the $1 \mathrm{H}-\mathrm{NMR}$ of $\beta-\mathrm{CD}, \beta-\mathrm{CD}-$ 2-aminobenzophenone, indicated downfield shift of $\mathrm{H}-\mathrm{C}(3)$ and $\mathrm{H}-\mathrm{C}(5)$ of cyclodextrin in the $\beta$-CD -2-amino benzophenone and $\beta$-CD-2-amino benzophenone-DMAD complex, compared to $\beta-C D$, confirming the formation of an inclusion complex of 2aminobenzophenone with $\beta$-CD. During complexation of 2-aminobenzophenone, $\beta$-CD solubilises the reactant, activates the carbonyl group and helps in the completion of the reaction with DMAD/DEAD. As usual $\beta-C D$ can be recovered and reused. This ecofriendly biomimetic protocol for the synthesis of quinoline-2,3-dicarboxylates, is a useful addition to green chemistry. 


\section{Chromenes}

Even though several potential applications in organic synthesis as well as bio-organic chemistry are associated with phosphonate functionality, which is a 'bioisostere' of ester moiety, derivatization through formation of phosphorus-carbon bond to obtain chromenyl phosphonates is not much explored (Moonen et al., 2004).

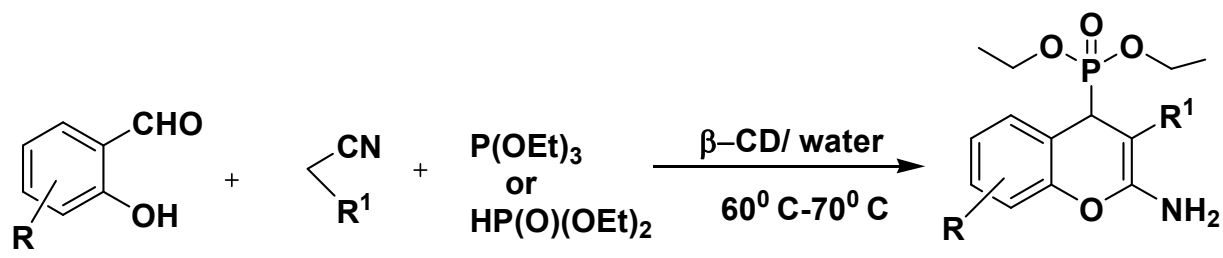

$\mathrm{R}=\mathrm{Cl}, \mathrm{Br}, \mathrm{I}, \mathrm{OH}, \mathrm{OMe} ; \mathrm{R}^{1}=\mathrm{CN}, \mathrm{COOEt}$

\section{Synthesis of 2-amino-3-cyano-4H-chromen-4-yl phosphonate derivatives}

Chromenes are a prominent class of compounds widely present in many natural products and are used in agrochemicals, cosmetics, and pigments (Ellis, 1977). Some of these 2amino-4H-chromene derivatives are reported as $\mathrm{Bcl}-2$ antagonists which are discovered through fluorescent polarization (FP) and exhibit synergy with several anticancer therapies under diverse mechanism of action (Das et al., 2009; Doshi et al., 2006). Limited number of synthetic methodologies have been reported till now for the synthesis of 2-amino- $4 \mathrm{H}$ chromenes by using various catalysts and additives. Indium (III) chloride was used as a lewis acid catalyst by Perumal etal in the synthesis of (2-amino- 3-cyano-4H-chromene-4-yl) phosphonic acid diethyl ester (Jayashree et al., 2009). Nageswar et al. in continuation of their efforts towards developing biomimetic organic synthetic approaches through supramolecular catalysis involving recyclable promoter such as $\beta-C D$, described a simple one pot three component preparation of 2-amino $4 \mathrm{H}$-chromen-4-yl phosphonates from several substituted salicylaldehydes, malononitrile/ethyl cyano acetate and triethyl phosphate or diethyl phosphonate. This is the first report on the synthesis of these chromen phosphonate derivatives by biomimetic synthetic strategy using $\beta$-cyclodextrin in water, under neutral conditions (Murthy et al., 2010).<smiles>CCOC(=O)C1=C(N)Oc2ccc(Br)cc2C1C(C#N)C(=O)OCC</smiles><smiles>CCOC(=O)CC1=C(N)C(CC(=O)OCC)Oc2ccc(-c3ccccc3)cc21</smiles>

Structures of Bcl-2 protein antagonists

Initially when authors attemped the synthesis of 2-amino-4H-chromen-4-yl phosphonate derivatives in water under catalyst-free conditions, they were not successful in getting the desired product. It was observed that when salicylaldehyde was solubilised in aqueous solution of $\beta-C D$ at $50^{\circ} \mathrm{C}, \beta-C D$-salicylaldehyde complex was formed and to this on addition of malononitrile followed by triethyl phosphate the corresponding 2 -amino- $4 \mathrm{H}$ chromen-4-yl- phosphonate formed in excellent yield (88\%), on stirring at $60^{\circ} \mathrm{c}-70^{\circ} \mathrm{C}$ for $3-4$ 
hrs. The same reaction, when carried out by replacing malononitrile with ethyl cyano acetate under similar reaction conditions obtained ethyl-2-amino-4-(diethoxy phosphonyl)- $4 \mathrm{H}-$ chromen-3-carboxylate in $82 \%$ yield.

The scope of this interesting reaction was extended and studied with various substituted salicylaldehydes keeping triethyl phosphate as a common substrate. It was reported that, substituents on the salicylaldehyde did not show significant effect on the product yields. However, when malononitrile was replaced with ethylcyanoacetate slight decrease in the product yields was observed. When triethyl phosphate was replaced with diethyl phosphonate as a third component in the reaction, the products were formed in lower yields in longer reaction times. All the products were characterized by spectral data. Investigations on NMR data of salicylaldehyde, $\beta-C D$, and $\beta$-CD-salicylaldehyde inclusion complex, revealed an upfield shift of $3-\mathrm{H}$ and $5-\mathrm{H}$ protons of the cyclodextrin in the $\beta-\mathrm{CD}-$ salicylaldehyde complex, when compared to $\beta-C D$, confirming the formation of an inclusion complex of salicylaldehyde from the secondary side of the $\beta$-cyclodextrin. The results clearly established that the reaction was proceeding through an inclusion phenomenon.

Thus an efficient, environ friendly, biomimetic synthetic approach for the preparation of 2-amino-4H-chromen - 4-yl phosphonates under neutral conditions by using $\beta$-CD as a supramolecular catalyst through host-guest complexation phenomenon was observed, which will be an useful addition to green chemistry.

\section{Quinoxalines}

Quinoxalines are a prominent class of nitrogen containing heterocycles, exhibiting various biological activities such as anti-viral, anti-bacterial, anti-biotic, anti- inflammatory and kinase inhibition. They are very important building blocks in the preparation of dyes, electroluminescent material, organic semiconductors, cavitands, and dehydroannulenes. Quinoxalines act as potential rigid subunits in macrocyclic receptors (Mizuno et al., 2002; Elwahy, 2000) for molecular recognition and chemically controllable switches (Crossley \& Jhonston, 2002).

In general many synthetic protocals have been developed for the preparation of quinoxaline derivatives. These include condensation of 1,2-diamines and 1,2-dicarbonyl compounds(Brown, 2004),1,4-addition of 1,2-diamines to diazenylbutenes(Aparicio et al.,2006), oxidative coupling of epoxides with ene-1,2-diamines(Antoniotti \& Dunach, 2002), oxidative cyclization of $\alpha$-hydroxy ketones with 1,2-diamines( Raw et al., 2004; Kim et al., 2005; Robinson \& Taylor, 2005; Cho et al., 2007), cyclization-oxidation of phenacyl bromides with 1,2-diamines by $\mathrm{HClO}_{4} \cdot \mathrm{SiO}_{2}$ (Das et al., 2007) and by using solid phase synthesis (Wu \& Ede,2001; Singh et al., 2003). Existing synthetic methodologies for quinoxaline system are rather limited in number and model when compared to their broad spectrum utility.

However these also suffered from many limitations such as use of expensive reagents, drastic reaction conditions, and complicated work-up procedures. In this context, Nageswar et al. during their work on cyclodextrin promoted biomimetic organic synthesis, developed a generally applicable and environmentally benign methodology for the synthesis of quinoxaline derivatives involving use of cyclodextrin as an efficient biomimetic catalyst (Madhav et al., 2009).

Initially, a representative reaction was conducted by the insitu formation of $\beta-C D$ complex of phenacyl bromide in water at $50^{\circ} \mathrm{C}$, followed by the addition of benzene-1, 2-diamine. The reaction mixture was stirred at $70^{\circ} \mathrm{C}$ for $2 \mathrm{hrs}$ resulting in 2-phenyl quinoxaline 
derivative. The scope of this methodology was extended to cover several substituted phenacyl bromides by reacting them with benzene 1, 2-diamine at 70。 $\mathrm{C}$ in water in presence of $\mathrm{CD}$ resulting in the corresponding quinoxalines in quantitative yields (87-92\%). This reaction is compatible with phenacyl bromides bearing electron-withdrawing and electrondonating substituents in the aromatic ring. All these reactions have proceeded efficiently to give impressive yields without the formation of any byproducts. This is because of the activation of phenacyl bromide by the complexation with $\beta$-cyclodextrin. The quinoxaline derivatives were isolated and identified by spectral data and by comparison with the known compounds. In all these reactions $\beta-C D$ can also be recovered and used for further runs. Solubility problems, longer reaction times, lower yields were the drawbacks when $\beta-C D$ was not used. The catalytic amount of $\beta-\mathrm{CD}$ (0.1 equiv) had no impact on the reaction progress, but when equimolar quantity was used yields improved.

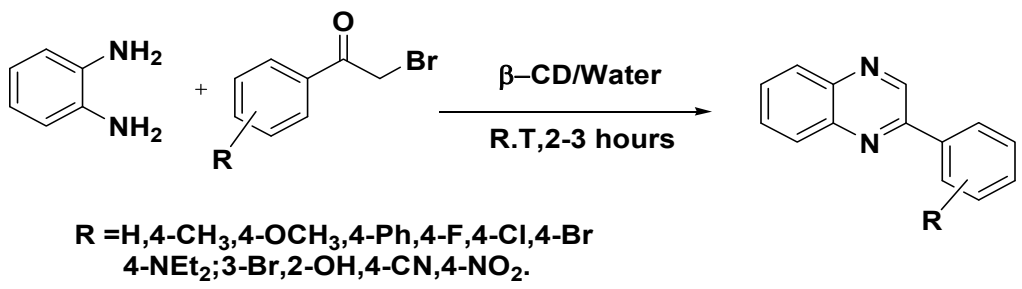

Biomimetic synthesis of quinoxalines in water

$\beta-C D$ solubilises phenacyl bromide by forming host-guest complex and activate carbonyl functionality to promote the reaction. Isolation of $\beta$-CD-phenacyl bromide complex and the study of ${ }^{1} \mathrm{H}$ NMR of $\beta$-CD, $\beta$-CD complex of phenacylbromide (1) and freeze-dried reaction mixture confirms the formation of $\mathrm{CD}$ - phenacyl bromide inclusion complex. The formation of inclusion complex from the secondary side of $\beta-\mathrm{CD}$ results in the up field shift of $\mathrm{H} 3, \mathrm{H} 5$ protons of $\beta-C D$ phenacylbromide complex when compared to $\beta-C D$.<smiles>Cc1cc2nc3ccc(N(C)C)cc3nc2cc1N</smiles>

Toluylene Red<smiles>Cc1cc2nc3cc(C)c(N)cc3[n+](-c3ccccc3Cl)c2cc1N</smiles>

\section{Safranin Biological Stain}

$\beta$-Cyclodextrin was proved to play a significant role by activating the phenacylbromide molecule to undergo cyclocondensation with benzene-1, 2-diamine. This straightforward simple aqueous phase approach to quinoxalines will be an useful addition to biomimetic chemistry.

\section{1, 2-disubstituted benzimidazole}

Benzimidazole is a potential heterocyclic pharmacophore responsible for a number of important pharmacological properties, such as anti-pyretic, antihistaminic, anti-allergic (Nakano et al., 2000), and anti-ulcerative (Scott et al., 2002). They are also effective against 
various viruses like influenza, human cyto- megalovirus, and HIV. Its derivatives exhibit anti-microbial, anti-tumour activities as well as act as topoisomerase inhibitors, Factor Xa inhibitors, and selective neuropeptide YY1 receptor antagonists. Broad range of diverse activities, expressed by benzimidazole containing structures has attracted the attention of researchers across the globe.

While working on various biomimetic approaches for a broad range of heterocyclic derivatives the synthesis of 1, 2-disubstitued benzimidazoles was attempted in our laboratory (un published work Shankar et al., 2010) by reacting 2 moles of benzaldehyde with one mole of benzene 1, 2-diamine in water in presence of $\beta$-cyclodextrin at room temperature. In general, the reaction was carried out by the insitu formation of the $\beta-C D$ complex of o-phenylenediamine in water followed by the addition of an aromatic aldehyde. The reaction mixture was stirred at room temperature to give the corresponding 1, 2-bis (aryl)-benzimidazoles in high yield (82\%). These reactions proceeded efficiently without the need of any metal or acid catalyst. The reaction goes to completion in a short time (3.5-4.5 h). These reactions also take place with $a-C D$ and $\gamma-C D$, with lesser yields. However, $\beta-C D$ has been chosen as the mediator, since it is inexpensive and easily accessible. Scope of the reaction has been extended to cover several substituted benzaldehydes as well as benzene 1 , 2-diamines. All the compounds were characterized by ${ }^{1} \mathrm{H}$ NMR, IR, and mass spectrometry. The catalytic activity of cyclodextrins for these reactions is established by the fact that no reaction was observed in the absence of cyclodextrin. Evidence for complexation between the amine and cyclodextrin is supported by $1 \mathrm{H}$ NMR spectroscopy. ${ }^{1} \mathrm{H}$ NMR spectra $\left(\mathrm{D}_{2} \mathrm{O}\right)$ of $\beta$-CD, $\beta$-CD- o-phenylenediamine complex were compared. There was an upfield shift of $\mathrm{H} 3$ and $\mathrm{H} 5$ protons of cyclodextrin in the $\beta$-CD-o-phenylene diamine complex.

After the reaction, the reaction mass was cooled to room temperature and $\beta-C D$ was filtered, washed with ice-cold water and dried. The recovered $\beta-C D$ was further used with the same substrates as a catalyst and checked for the yields and catalytic activity of $\beta$-CD. It was observed that the yields of 1-benzyl-2-phenyl-1H-benzo[d]imidazole after two to three recycles were nearly the same. In summary, a neutral aqueous phase synthesis of various 1 , 2-bis (aryl)-benzimidazoles was developed by the reaction of the corresponding ophenylenediamine with aldehydes, under biomimetic conditions in the presence of $\beta$ cyclodextrin. These cyclodextrin-mediated aqueous phase reactions are very useful both from economical and environmental view. $\beta$-Cyclodextrin, apart from being nontoxic, is also considered as metabolically safe. This simple straightforward and environmentally benign methodology may find widespread application in organic and medicinal chemistry.<smiles>COc1ccc2[nH]c(S(=O)Cc3ncc(C)c(OC)c3C)nc2c1</smiles>

Omeprazole Antiulcer Drug<smiles>CCOc1nc2cccc(C(=O)O)c2n1Cc1ccc(-c2ccccc2-c2nn[nH]n2)cc1</smiles>

Candesartan Angiotensin receptor antagonist TCV-116<smiles>COC(=O)Nc1nc2cc(C(=O)c3ccccc3)ccc2[nH]1</smiles>

Mebendazole Antihelmintic drug 
In conclusion, we have presented here an improved methodology for the selective synthesis of 1, 2-disubstituted benzimidazoles by the condensation of o-phenylenediamine and aldehydes using $\beta-C D$ as a supramolecular catalyst.

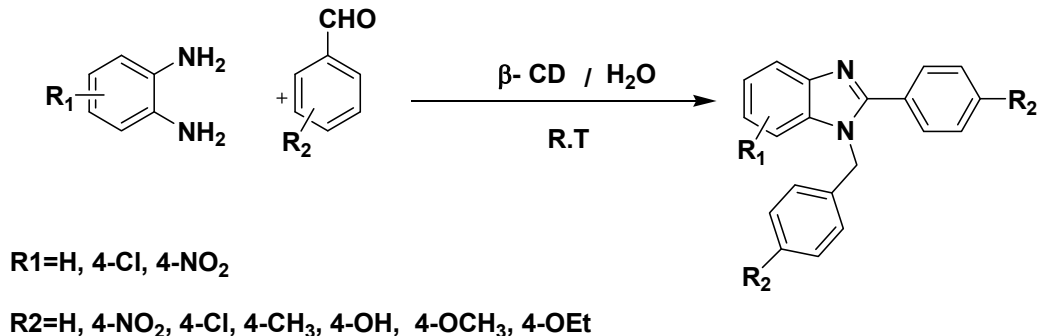

\section{Synthesis of 1, 2-disubstituted benzimidazoles}

\section{Conclusion}

The growth of literature on cyclodextrins from their discovery till now showcases the significance of cyclodextrin chemistry and their potential molecular receptor ability involving host-guest complexation and its subsequent applications in a wider arena. Cyclodextrins with their unique hydrophobic cavity, activates the guest molecules with the assistance of hydroxyl groups, to promote various organic transformations, in aqueous medium under neutral conditions. Cyclodextrins in combination with water as reaction medium will further contribute to attain new vistas in the development of novel green chemistry protocols in the future.

\section{Acknowledgements}

We thank CSIR, New Delhi for fellowships to S. N. M.; B.M.; J. S.

\section{References}

Antoniotti, S.; Dunach, E. (2002). Tetrahedron Lett., 43, 2002, 3971-3973.

Aparicio, D.; Attanasi, O. A.; Filippone, P.; Ignacio, R.; Lillini, S.; Mantellini, F.; Palacios, F.; Delos Santos, J. M. (2006). J. Org. Chem. 71, 2006, 5897-5905.

Back, T. G. (1999). Organoselenium Chemistry: A Practical Approach; Oxford University Press: Oxford.

Bailey, N.; Dean, A. W.; Judd, D. B.; Middlemiss, D.; Storer, R.; Stephen, P. W.(1996). Bioorg. Med. Chem. Lett., 6, 1996, 1409-1414.

Bassetti, M.; D’ Annibale, A.; Fanfoni, A.; Minissi, F. (2005). Org. Lett. 7, 2005, 1805-1808.

Benazzouz, A.; Boraud, T.; Dubedat, P.; Boireau, A.; Stutzmann, J.-M.; Gross, C.(1995).Eur. J. Pharmacol, 284, 1995, 299-307.

Bergstrom, D.E, ; Zhang,P; Zhou. J. (1994). J.Chem.Soc., Perkin Trans.1, 1994, 3029-3034.

Binder, J. T.; Kirsch, S. F.(2006). Org. Lett., 8, 2006, 2151-2153.

Brown, D. J. In Chemistry of Heterocyclic Compounds, Quinoxalines Supplements II; Taylor, E. C., Wipf, P., Eds.; John Wiley and Sons: New Jersey, 2004.

Bryce, M. R.; Acheson, M. R.; Rees, A. J. (1983). Heterocycles, 20, 1983, 489-495.

Cao, R.; Liu, C.; Liu, L. (1996). Org. Prep. Proced. Int., 28, 1996, 215-216. 
Cho, C. S.; Ren, W. X. (2007). J. Organomet. Chem., 692, 2007, 4182-4186.

Cho, C. S.; Renb, W. X.; Shim, S. C. (2007). Tetrahedron Lett., 48, 2007, 4665-4667.

Crossley, J. C.; Johnston, L. A. (2002). Chem. Commun., 2002, 1122-1123.

Cyr, D. J. S.; Martin, N.; Arndtsen, B. A. (2007). Org. Lett., 9, 2007, 449-452.

Dabiri, M.; Salehi, P.; Mostafa, B.; Nikcheg, M. S.(2008). Tetrahedron Lett., 49, 2008, 53665368.

Das, B.; Venkateswarlu, K.; Suneel, K.; Majhi, A. (2007). Tetrahedron Lett. 48, 2007, 5371-5374.

Das, S. G.; Doshi, J. M.; Tian, D.; Addo, S. N.; Srinivasan, B.; Hermanson, D. L.; Xing, C. (2009). J. Med. Chem., 52, 2009, 5937-5949.

Demarco, P. V.; Thakkar, A. L. (1970). J. Chem. Soc. Chem. Commun. 1970, $2-4$.

De Souza, M. V. N. (2005). Mini- Rev. Org. Chem., 2, 2005, 139-145.

Dondoni, A.(1998). Synthesis, 1998, 1681-1706.

Doshi, J. M.; Tian, D.; Xing, C. (2006). J. Med. Chem., 49, 2006, 7731-7739.

D'Souza, Lipkowitz, K. B. (1998). Chem. Rev., 98, 1998, 1741-2076.

Edmondson, S.; Danishefsky, S. J.; Sepp-Lorenzino, L.; Rosen, N. (1999). J. Am. Chem. Soc., 121, 1999, 2147-2155.

Ellis, G. P. (1977). In The Chemistry of Heterocyclic Compounds. Chromenes, Harmones, and Chromones; Weissberger, A., Taylor, E. C., Eds.; John Wiley: New York, 1977; pp 11-139. Chapter II.

Elwahy, A. H. M. (2000). Tetrahedron, 56, 2000, 897-907.

Firouzabadi, H.; Iranpoor, N.; Sobhani, S. (2004). Synth. Commun., 34, 2004, 1463-1471.

Firouzabadi, H.; Iranpoor, N.; Sobhani, S.; Amoozgar, Z. (2004). Synthesis, 2004, 1771-1774.

Fu, C.; Ma, S. (2005). Eur. J. Org. Chem., 2005, 3942-3945.

Gabriele, B.; Mancuso, R.; Salerno, G.; Ruffolo, G.; Plastina, P. (2007). J. Org. Chem., 72, 2007, 6873-6877.

Gallagher, G.; Lavanchy, P. G.; Wilson, J. W.; Hieble, J. P.; DeMarinis, R. M. (1985). J. Med. Chem., 28, 1985, 1533-1536.

Goldstein, B. M.; Kennedy, S. D.; Hennen, W. J. (1990). J. Am. Chem. Soc., 112, 1990, 82658268.

Grigoras, M.; Conduruta, D. G. J. (2006). Inclusion Phenom. Macrocycl. Chem. 54, 2006, 101-107.

Hadjipavlou-Litina, D. J.; Geronikaki, A. A. (1998). Drug Des. Discovery, 15, 1998, 199-206.

Haviv, F.; Ratajczyk, J. D.; DeNet, R. W.; Kerdesky, F. A.; Walters, R. L.; Schmidt, S. P.; Holms, J. H.; Young, P. R.; Carter, G. W.(1988). J. Med. Chem., 31, 1988, 1719-1728.

Hendrickson, J. B.; Rees, R.; Templeton, J. F. (1964). J. Am. Chem. Soc., 86, 1964, 107-111.

Hollingworth, G. J.; Perkins, G.; Sweeney, J. B. (1996). J. Chem. Soc., Perkin Trans.11996, 19131919.

Hu, Y. Z.; Zhang, G.; Thummel, R. P. (2003). Org. Lett., 5, 2003, 2251-2253.

Iorga, B.; Eymery, F.; Savignac, P. (1999). Tetrahedron, 55, 1999, 2671-2686.

James, D. S.; Fanta, P. E. (1962). J. Org. Chem., 27, 1962, 3346-3348.

Jayashree, P.; Shanthi, G.; Perumal, P. T. (2009). Synlett, 2009, 917-920.

Jenekhe, S. A.; Lu, 1.; Alam, M. M.(2001). Macromolecules, 34, 2001, 7315-7324.

Jiang, B.; Dong, J. J. ; Jin, Y.; Long Du, X.; Xu, M. (2008). Eur. J. Org. Chem., 2008, 2693-2696.

Kaboudin, B.(2003). Tetrahedron Lett., 44, 2003, 1051-1053.

Kazmaier, U.; Ackermann, S. (2005). Org. Biomol. Chem., 3, 2005, 3184-3187.

Kazzouli, S. EI.; Raboin, S. B.; Mouadbib, A.; Guillaumet, G. (2002). Tetrahedron Lett., 43, 2002, 3193-3196.

Kim, S. Y.; Park, K. H.; Chung, Y. K. (2005). Chem. Commun., 2005, 1321-1323.

Kotora, M.; Negishi, E. (1997). Synthesis, 1997, 121-128. 
Koketsu, M.; Mio, T.; Ishihara, H.(2004). Synthesis, 2004, 233-236.

Koketsu, M.; Tanaka, H.; Ishihara, H. (2005). Chem. Lett., 34, 2005, 1260-1261.

Koketsu, M.; Kogami, M.; Ando, H.; Ishihara, H. (2006). Synthesis, 2006, 0031-0036.

Kumar, V. P.; Narender, N.; Sridhar, R.; Nageswar, Y. V. D.; Rao, K. R.(2007). Synthetic Commun., 37, 2007, 4331-4336.

Lipshutz, B. H.; Frieman, B.; Birkedal, H.(2004) Org. Lett., 6, 2004, 2305-2308.

Mabon, R.; Richecoeur, A. M. E.; Sweeney, J. B. (1996). J. Org. Chem., 64,1999,328-329.

Mabon, R.; Richecoeur, A. M. E.; Sweeney, J. B. (2002). Tetrahedron 58, 2002, 9117-9129.

Madhav, B.; Murthy, S. N.; Reddy, V. P.; Nageswar, Y. V. D. (2009). Tetrahedron Lett., 50, 2009, 6025-6028.

Madhav, B.; Murthy, S. N.; Rao, K. R.; Nageswar, Y. V. D. (2010). Helv. Chim. Acta., 93, 2010, 257-260.

Martin, L.M.; Hu, B.-H.(1999). Tetrahedron Lett., 40, 1999, 7951-7953.

Martinez, R.; Ramon, D. J.; Yus, M. (2007). Eur. J. Org. Chem., 2007, 1599-1605.

Maryanoff, B. E.; Reitz, A. B. (1989). Chem. Rev., 89, 1989, 863-927.

McNaughton, B. R.; Miller, B. L. (2003). Org. Lett., 5, 2003, 4257-4259.

Miao, S.; Andersen, R. (1991). J. Org. Chem., 56, 1991, 6275-6280.

Michael, J. P.(2007). Nat. Prod. Rep., 24, 2007, 223-246.

Mierde, H. V.; Voort, P. V.; Vos, D. D.; Verpoort, F. (2008). Eur. J. Org. Chem. 2008, 16251631.

Mizuno, T.; Wei, W. H.; Eller, L. R.; Sessler, J. L. J. Am. Chem. Soc. 2002, 124, 1134-1135.

Moonen, K.; Laureyn, I.; Stevens, C. V. (2004). Chem. Rev., 104, 2004, 6177-6216.

Muscia, G. C.; Bollini, M.; Carnevale, J. P.; Bruno, A. M.; Asis, S. E. (2006). Tetrahedron Lett., 47, 2006, 8811-8815.

Murthy, S. N.; Madhav, B.; Kumar, A. V.; Rao, K. R.; Nageswar, Y. V. D. (2009). Tetrahedron, 65, 2009, 5251-5256.

Murthy, S. N.; Madhav, B.; Kumar, A. V.; Rao, K. R.; Nageswar, Y. V. D. (2009). Helv. Chim. Acta., 92, 2009, 2118-2124..

Murthy, S. N.; Madhav, B.; Reddy, V. P.; Nageswar, Y. V. D. (2010). Tetrahedron Lett., 51, 2010, 3649-3653.

Mustafa, S.M.; Nair, V.A.; Chittoor, J. P.; Krishnapillai, S. (2004). Mini-Rev. Org. Chem., 1, 2004, 375-385.

Mylari, B. L.; Larson, R.; Beyer, T. A.; Zembrowski, W. J.; Aldinger, C. E.; Dee, M. F.; Siegel, T. W.; Singleton, D. H.(1991). J. Med. Chem., 34, 1991, 108-122.

Nagel, A. A.; Liston, D. R.; Jung, S.; Mahar, M.; Vincent, L. A.; Chapin, D.; Chen, Y. L.; Hubbard, S.; Ives, J. L.; Jones, S. B.(1995). J. Med. Chem., 38, 1995, 1084-1089.

Narender, M.; Reddy, M. S.; Kumar, V. P.; Reddy, V. P.; Nageswar, Y. V. D.; Rao, K. R. (2007). J. Org. Chem., 72, 2007, 1849-1851.

Narender, M.; Reddy, M. S.; Kumar, V. P.; Srinivas, B.; Sridhar, R.; Nageswar, Y. V. D.; Rao, K. R. (2007). Synthesis, 2007, 3469-3472.

Nakano, H.; Inoue, T.; Kawasaki, N.; Miyataka, H.; Matsumoto, H.; Taguchi, T.; Inagaki, N.; Nagai, H.; Satoh, T.(2000). Bioorg. Med. Chem., 8, 2000, 373-380.

Nicolaou, K.C.; King, N. P.; Finlay, M. R. V .; Roschangar, F.; Vourloumis, D .; Vallberg, h.; Sarabia, F .; Ninkovic, S .; Hepworth, D. (1999). Bioorg. Med. Chem., 7, 1999, 665-697.

Palmer, P. J.; Trigg, R. B.; Warrington, J. V. (1971). J. Med. Chem., 14, 1971, 248-251.

Patel, D. V.; Rielly-Gauvin, K.; Ryono, D. E.; Free, C. A.; Rogers, W. L.; Smith, S. A.; DeForrest, J. M.; Oehl, R. S.; Petrillo, E. W. (1995). J. Med. Chem., 38, 1995, 4557. 
Patt, W. C.; Hamilton, H. W.; Taylor, M. D.; Ryan, M. J.; Taylor, D. G. Jr.; Connolly, C. J. C.; Doharty, A. M.; Klutchko, S. R.; Sircar, I.; Steinbaugh, B. A.; Bately, B. L.; Painchand, C. A.; Rapundalo, S. T.; Michniewicz, B. M.; Olzon, S. C. J.(1992). J. Med. Chem., 35, 1992, 2562-2572.

Phoon, C. W.; Ng, P. Y.; Ting, A. E.; Yeo, S. L.; Sim, M. M.(2001). Bioorg. Med. Chem. Lett., 11, 2001, 1647-1650.

Raw, S. A.; Wilfred, C. D.; Taylor, R. J. K. (2004). Org. Biomol. Chem., 2, 2004, 788-796.

Robinson, R. S.; Taylor, R. J. K. (2005). Synlett., 2005, 1003-1005.

Sapountzis, I.; Dude, H.; Lewis, R.; Gommermann, N.; Knochel, P.(2005). J. Org .chem., 70, 2005, 2445-2454.

Scott, L. J.; Dunn, C. J.; Mallarkey, G.; Sharpe, M. (2002). Drugs , 62, 2002, 1503.

Shankar, J.; Karnakar,K.; Srinivas, B.; Nageswar, Y. V. D. (2010). Tetrahedron Lett., 51, 2010, 3938-3939.

Shankar, J.; Karnakar, K.; Nageswar, Y. V. D. (2010). (Unpublished results-part of the thesis of Shankar. J.)

Shindo, M.; Yoshimura, Y.; Hayashi, M.; Soejima, H.; Yoshikawa, T.; Matsumoto, K.; Shishido, K. (2007). Org. Lett., 9, 2007, 1963-1966.

Shiraishi, H.; Nishitani, T.; Nishihara, T.; Sakaguchi, S.; Ishii, Y.(1999), Tetrahedron, 55, 1999, 13957-13964.

Singh, S. K.; Gupta, P.; Duggineni, S.; Kundu, B. (2003). Synlett., 2003, 2147-2150.

Sohn, S. K.; Chang, M. S.; Choi, W. S.; Kim, K. W.; Woo, T. W.; Lee, S. B.; Chung, Y. K.(1999). Can. J. Physiol. Pharmacol., 77, 1999, 330-338.

Sridhar, R.; Srinivas, B.; Madhav, B.; Reddy, V. P.; Nageswar, Y. V. D.; Rao, K. R. (2009). Can. J. Chem., 87, 2009, 1704-1707.

Srivastava, P. C.; Robins, R. K.(1983). J. Med. Chem,. 26, 1983, 445-448.

Stowasser, B.; Budt, K.-H.; Jian-Qi, L.; Peyman, A.; Ruppert, D. (1992). Tetrahedron Lett., 33, 1992, 6625.

Sundberg, R. J.(1996). Comprehensive Heterocyclic Chemistry, Katritzky, A. R.; Rees, C. W. (Ed.)), 149--, Pergamon Press, Oxford.

Suresh, K. K.; Sandhya, B.; Himanshu, G.(2009). Mini-Rev. Med. Chem., 7, 2009, 1648-1654.

Szejtli, J.; Osa, T. (1996). In Comprehensive Supramolecular Chemistry, Pergamon Press. New York, 1996, Vol. 3.

Taylor, E. C.; Heindel, N. D. (1967) J. Org. Chem., 32, 1967, 1666-1667.

Tokunaga, T.; Hume, W. E.; Umezome, T.; Okazaki, K.; Ueki, Y.; Kumagai, K.; Hourai, S.; Nagamine, J.; Seki, H.; Taiji, M.; Noguchi, H.; Nagata, R. (2001). J. Med. Chem., 44, 2001, 4641-4649.

Vieira, T. O.; Alper, H. (2007). Chem. Commun., 2007, 2710-2711.

Wirth, T. (2000). Organoselenium Chemistry. Modern Developments in Organic Synthesis; Springer: Berlin.

Wu, J.; Xia, H. G.; Gao, K. (2006). Org. Biomol. Chem., 4, 2006, 126-129.

Wu, Z.; Ede, N. J. (2001). Tetrahedron Lett., 42, 2001, 8115-8118.

Xin-Yuan, L.; Ding, P.; Jie-Sheng, H.; Chi-Ming, C. (2007). Org. Lett., 9, 2007, 2645-2648.

Zaveri, N. T.; Jiang, F.; Olsen, C. M.;Deschamps, J. R.; Parrish, D.; Polgar, W.; Toll, L. (2004). J. Med. Chem., 47, 2004, 2973-2976.

Zhang, L.; Wu, J. (2007). Adv. Synth. Catal., 349, 2007, 1047-1051.

Zhang, X.; Shetty, S.; Jenekhe, S. A. (1999). Macromolecules, 32, 1999, 7422-7429. 


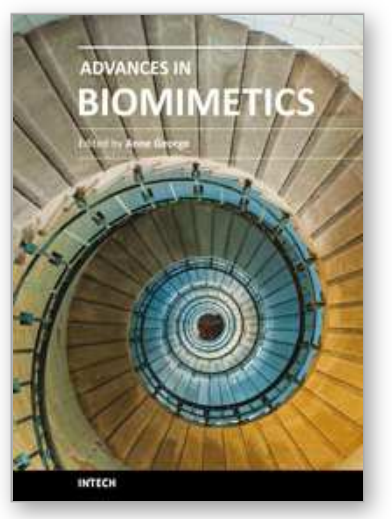

\author{
Advances in Biomimetics \\ Edited by Prof. Marko Cavrak
}

ISBN 978-953-307-191-6

Hard cover, 522 pages

Publisher InTech

Published online 26, April, 2011

Published in print edition April, 2011

The interaction between cells, tissues and biomaterial surfaces are the highlights of the book "Advances in Biomimetics". In this regard the effect of nanostructures and nanotopographies and their effect on the development of a new generation of biomaterials including advanced multifunctional scaffolds for tissue engineering are discussed. The 2 volumes contain articles that cover a wide spectrum of subject matter such as different aspects of the development of scaffolds and coatings with enhanced performance and bioactivity, including investigations of material surface-cell interactions.

\title{
How to reference
}

In order to correctly reference this scholarly work, feel free to copy and paste the following:

Y. V. D. Nageswar, S. Narayana Murthy, B. Madhav and J. Shankar (2011). Recent Advances in Biomimetic Synthesis Involving Cyclodextrins, Advances in Biomimetics, Prof. Marko Cavrak (Ed.), ISBN: 978-953-307191-6, InTech, Available from: http://www.intechopen.com/books/advances-in-biomimetics/recent-advances-inbiomimetic-synthesis-involving-cyclodextrins

\section{INTECH}

open science | open minds

\section{InTech Europe}

University Campus STeP Ri

Slavka Krautzeka 83/A

51000 Rijeka, Croatia

Phone: +385 (51) 770447

Fax: +385 (51) 686166

www.intechopen.com

\section{InTech China}

Unit 405, Office Block, Hotel Equatorial Shanghai

No.65, Yan An Road (West), Shanghai, 200040, China

中国上海市延安西路65号上海国际贵都大饭店办公楼405单元

Phone: +86-21-62489820

Fax: +86-21-62489821 
(C) 2011 The Author(s). Licensee IntechOpen. This chapter is distributed under the terms of the Creative Commons Attribution-NonCommercialShareAlike-3.0 License, which permits use, distribution and reproduction for non-commercial purposes, provided the original is properly cited and derivative works building on this content are distributed under the same license. 